\title{
Prognostic factors influencing prolonged ventilation after open mitral valve surgery
}

\author{
Supomo
}

Thorax and Cardiovascular Surgery Division, Department of Surgery, Faculty of Medicine Public Health and Nursing, Universitas Gadjah Mada

Correspondence: Supomo; email: supomo.tkv@mail.ugm.ac.id

\begin{abstract}
Objective: To determine prognostic factors influencing prolonged ventilation after surgery in our hospital. Method: Seventy-five patients fulfilled inclusion criteria were included in this retrospective cross-sectional study. Prognostic factors analyzed were age, chronic pulmonary disease, heart failure (NYHA class function), left ventricular (LV) dysfunction (based on ejection fraction), recent myocardial infarction, pulmonary hypertension (PH), duration of cardiopulmonary bypass (CPB), ischemic time and aorta clamp time, which were analyzed in relation to prolonged ventilation after open mitral valve surgery. Results: Subjects were 75 patients aged between 19 and 62 years old (mean 39.76, SD 11.44) whom underwent open mitral valve repair or replacement surgery. Twenty-three patients $(30.67 \%)$ had prolonged ventilation ( $\geq 24$ hours) after surgery. Bivariate analysis showed there were no significant correlation between age, heart failure, $\mathrm{PH}$ and LV dysfunction. There are different with statistically significance between groups $(p<0.05)$. Conclusions: In this study, almost one-third of patients had prolonged ventilation after surgery. Factors influencing this morbidity were the duration of ischemic time, aorta clamp time and CPB. Age, heart failure, LV dysfunction and PH were not statistically related to the prolonged ventilation event.
\end{abstract}

Keywords: mitral valve surgery; morbidity; prolonged ventilation; prognostic factors

\section{INTRODUCTION}

The global epidemiology of valvular heart disease has changed dramatically recently. Rheumatic heart disease (RHD) which was the main cause of valvular heart disease prior to World War II, has now reduced its incidence, due to the development of new antibiotics and improvement of healthcare system, especially in developing countries. At the same time, life expectancy increases, and the prevalence of agerelated valvular heart disease (e.g. degenerative valve disease) increases. The presence of valvular heart disease (VHD) has a statistically significant impact on mortality, underscoring the fact that VHD is a significant health problem. ${ }^{1}$

Surgical intervention is the main management of moderate to severe valvular heart disease. Despite the expensive cost for the procedure, access to medical procedures increases with economic improvement. ${ }^{2}$ Cardiac surgery itself is an operation performed to correct anatomic or cardiac function. Types of cardiac surgery include Coronary Artery Bypass Graft (CABG) surgery, heart valve repair or replacement surgery and other 
operations. This heart surgery procedure is can be performed in two ways, by stopping the heart temporarily (on-pump) or surgery with the heart that is still throbbing (off-pump). ${ }^{3}$

Although postoperative mortality is the most important clinical data, mortality alone is no longer considered sufficient to assess patient's outcome. It is clearly recognized that non-fatal postoperative complications can significantly affect the patient's functional status and quality of life. Therefore, the identification of factors and the calculation of risk to the level of morbidity in cardiac surgery patients can provide valuable insights into improving the quality of patient care. ${ }^{4}$ In addition to being a widely used predictor of mortality, EuroSCORE has proven to be a good predictor of postoperative morbidity in cardiac surgery. ${ }^{5}$

From the prior studies by Priyatno ${ }^{6}$ and Asmaya $^{7}$, it was found that the most common post mitral valve surgery morbidity found in Dr. Sardjito General Hospital was postoperative prolonged ventilation, which is defined as the need of mechanical ventilation until $\geq 24$ hours post-surgery. The need of prolonged ventilation certainly brings medical, social, and economic implications directly to the patients. Although the identification of factors and the calculation of risks to the level of morbidity in cardiac surgery patients is very useful, there has never been any research on prognostic factors that affect prolonged ventilation after mitral valve surgery at Dr. Sardjito General
Hospital.

\section{METHODS}

This study was a retrospective crosssectional study. A total of 75 patients who met the inclusion criteria (patients underwent mitral valve surgery in the 2012-2017 period at Dr. Sardjito General Hospital) were included by purposive sampling in this study. The exclusion criteria used were incomplete medical record data, the patient underwent nonsurgical correction or a patient with a history of previous heart surgery. Preoperative factors consist of age, chronic lung disease, heart failure, left ventricular dysfunction (assessed from the ejection fraction), recent MI (myocardial infarction in the past 90 days) and pulmonary hypertension while intraoperative factors were the duration of $\mathrm{CPB}$, ischemic time and aortic clamp time. The dependent variable is the incidence of prolonged ventilation ( $\geq 24$ hours) postoperatively. The correlation between independent and dependent variables was analyzed statistically.

\section{RESULTS AND DISCUSSIONS}

Subjects were aged between 19 years and 62 years (mean age 39.76 years with a standard deviation of 11.44), with 2 subjects aged $\geq 60$ years and 73 subjects aged $<60$ years. In the age group $\geq 60$ years, there were $1.3 \%$ morbidity ( 1 subject). While in the $<60$ years group, morbidity was found in 22 (29.3\%) subjects. In the age group $\geq 60$ years, bivariate analysis 
performed with Chi square found $p=0.548$ with a confidence level $<0.05$. So it was concluded that age $\geq 60$ years did not significantly influence the incidence of postoperative morbidity.

Mortality and morbidity of surgery increase with increasing age in patients undergoing surgery. Although this risk is partly a result of increased comorbidity, age is an independent and strong risk factor for morbidity. ${ }^{8}$ Patients with age above 50 years have mortality and morbidity risk factors in patients with ICU care because patients aged over 50 years usually experience a lot of comorbid factors. 9 In the research by Ruiz et al., it was found that the occurrence of atherosclerosis is accelerated with increasing age. ${ }^{9}$ The effect of advanced age on patients is doubled. In the elderly it is characterized by an increase in circulating fibrinogen and factor VII. This damage contributes to increasing thrombogenesis through the effects of damage to endothelial function with disruption of fibrinolytic activity and coronary vasodilator response. ${ }^{10}$ In this study it was found that age $\geq 60$ years had no statistically significant effect on the incidence of morbidity (prolonged ventilation) after mitral valve surgery. This research finding were contrast to Nashef's research, said that age $\geq 60$ years has an effect on postoperative cardiac morbidity. ${ }^{11}$ This difference result is probably associated with the different anatomical characteristics and life expectancy of Europeans from those of
Indonesians, and also the number of subject samples was too small (only 2 patients out of a total of 75 patients).

In the data of patients with symptoms of heart failure, there were three classes of subjects, namely subjects who had symptoms of heart failure according to NYHA functional classes I, II and III. There were 5 patients included in the NYHA Functional Class I group, in which 1 subject (1.33\%) with morbidity and 4 subjects (5.33\%) without morbidity. In the NYHA Group Functional Class II there were 61 subjects, of which 20 (26.67\%) with morbidity and 41 subjects (54.67\%) without morbidity. In the NYHA Group III Functional Class there were 9 subjects, of which 2 (26.7\%) with morbidity and 7 subjects (9.33\%) without morbidity. Pvalue was 0.705 so it was concluded that the degree of preoperative heart failure was not related to the incidence of prolonged ventilation after mitral valve surgery.

A study by Azarfarin (2014), revealed that patients with heart failure functional classes III and IV increased ICU length of stay, postoperative stroke incidence and postoperative kidney failure. ${ }^{12}$ In this study the status of patients with clinical heart failure functional class IV was not found. This is likely because patients with functional IV grade heart failure rarely achieve optimal conditions for surgery. A previous study found that patients with clinical functional class III and IV heart failure had 3 years lower survival rates 
than patients with clinical I and II functional classes. ${ }^{13}$

Table 1. Patients Demographic and the Incidence of Prolonged Ventilation

\begin{tabular}{lccc}
\hline \multicolumn{1}{c}{ Variables } & $\mathrm{n}(\%)$ & \multicolumn{2}{c}{ Ventilation duration } \\
& & $\geq 24$ hours (\%) & $<24$ hours (\%) \\
\hline Age & & & \\
$\quad<60$ years old & $73(97.33)$ & $22(29.33)$ & $51(68)$ \\
$\geq 60$ years old & $2(2.67)$ & $1(1.33)$ & $1(1.33)$ \\
Chronic lung disease & & & \\
Positive & $0(0)$ & $0(0)$ & $0(0)$ \\
Negative & $75(100)$ & $23(30.67)$ & $52(69.33)$ \\
Heart failure (NYHA class function) & & & \\
CHF cf I (NYHA 1) & $5(6.67)$ & $1(1.33)$ & $4(5.33)$ \\
CHF cf II (NYHA 2) & $61(81.33)$ & $20(26.67)$ & $41(54.67)$ \\
CHF cf III (NYHA 3) & $9(12)$ & $2(2.67)$ & $7(9.33)$ \\
CHF cf IV (NYHA 4) & $0(0)$ & $0(0)$ & $0(0)$ \\
Left ventricular (LV) dysfunction & & & \\
Normal (LVEF >50\%) & $66(88)$ & $20(26.67)$ & $46(61.33)$ \\
Moderate (LVEF 30-50\%) & $9(12)$ & $3(4)$ & $6(8)$ \\
Severe (LVEF <30\%) & $0(0)$ & $0(0)$ & $0(0)$ \\
Recent MI & & & \\
Positive & $0(0)$ & $0(0)$ & $0(0)$ \\
Negative & $75(100)$ & $23(30.67)$ & $52(69.33)$ \\
Pulmonal hypertension & & & $18(24)$ \\
Mild & $22(29.33)$ & $4(5.33)$ & $17(22.67)$ \\
Moderate & $24(32.00)$ & $7(9.33)$ & $17(22.67)$ \\
Severe & $29(38.67)$ & $12(16)$ & \\
\hline
\end{tabular}

Preoperative left ventricular function impairment was defined as left ventricular ejection fraction (LVEF) $<50 \%$ in measurements using preoperative echocardiography. In this study, there were 9 patients with left ventricular function impairment, with 3 patients (4\%) having postoperative morbidity and $6(8 \%)$ without postoperative morbidity. In the group without impaired ventricular function there were 66 subjects, of which 20 subjects (26.67\%) with morbidity and 46 (61.33\%) without postoperative morbidity. $\mathrm{P}$-value was found to be 0.853 so it can be concluded that there was no significant relationship between impaired left ventricular function before surgery and postoperative prolonged ventilation morbidity.

The vital function of the left ventricle is to pump blood to all organs of the body including the vital organs such as brain, kidneys and lungs. In postoperative patients with poor left ventricular function capital coupled with severe operating stressors will result in organ damage due to oxygen supply and food that is not optimal. 
The damage can manifest as postoperative stroke, impaired renal function or prolongation of ventilator use due to impaired development of less optimal pulmonary ventilation. ${ }^{5}$

In the pulmonary hypertension data, there were three groups of subjects, namely subjects with mild pulmonary hypertension (pulmonary artery systolic pressure 25-40 $\mathrm{mmHg}$ ), moderate (pulmonary artery systolic pressure 41-55 $\mathrm{mmHg}$ ) and severe (pulmonary artery systolic pressure $>55 \mathrm{mmHg}$ ). There were 22 patients included in the mild pulmonary hypertension group, in which 4 subjects
(5.33\%) with morbidity and 18 subjects (24\%) without morbidity. In the group of patients with moderate pulmonary hypertension there were 24 subjects, of which 7 (9.33\%) with morbidity and 17 subjects (22.67\%) without morbidity. In the group of patients with severe pulmonary hypertension there were 29 subjects, of which 12 (16\%) with morbidity and 17 subjects $(22.67 \%)$ without morbidity. Pvalue was 0.202 , so it was concluded that the degree of preoperative pulmonary hypertension was not related to the incidence of prolonged ventilation after mitral valve surgery.

Table 2. Pearson's Chi-square test

\begin{tabular}{lccc}
\hline \multicolumn{1}{c}{ Variables } & \multicolumn{2}{c}{ Ventilation duration } & p-value \\
& 224 hours & $<24$ hours & \\
\hline Age & 22 & 51 & 0.548 \\
$<60$ years old & 1 & 1 & \\
260 years old & & & \\
Heart failure & 1 & 4 & \\
NYHA 1 & 20 & 41 & \\
NYHA 2 & 2 & 7 & \\
NYHA 3 & 0 & 0 & \\
NYHA 4 & & & \\
LV dysfunction & 20 & 46 & \\
Normal & 3 & 6 & 0.853 \\
Moderate & 0 & 0 & \\
Severe & & & \\
Pulmonal hypertension & 4 & 18 & \\
Mild & 7 & 17 & 0.01 \\
Moderate & 12 & $72^{\prime} 09^{\prime \prime}$ & 0.02 \\
Severe & $112^{\prime} 53^{\prime \prime}$ & $60^{\prime} 12^{\prime \prime}$ & 0.02 \\
Aorta Clamp (median) & $103^{\prime} 35^{\prime \prime}$ & $104^{\prime} 05^{\prime \prime}$ & \\
Ischemic Time (median) & $139^{\prime} 08^{\prime \prime}$ & & \\
CPB duration (median) & & &
\end{tabular}

For intraoperative data, we analyzed CPB duration, aortic clamp and ischemic time in all patients. The median values for duration of CPB, aortic clamp and ischemic time in living patients with positive morbidity were 139'08", 103'35" and 
112'53", respectively, while those with negative morbidity were 72'09", 60'12" and 104'05". Chi-square analysis performed on these three variables obtained a $p$-value of 0.02 for the duration of CPB and ischemic time and 0.01 for the aorta clamp time. Thus it is said that the variable duration of $\mathrm{CPB}$, aortic clamp time and ischemic time are significantly associated with prolonged ventilation after mitral valve surgery.

This finding resembles the results of Azarfarin's (2014) study of factors related to the increased of length of stay after open heart surgery which stated that age $>50$ years, duration of surgery and CPB duration had a significant effect on ICU length of stay. ${ }^{12}$ Another study that discussed the duration of CPB was carried out by Salis et al. (2008) which states that CPB duration is an independent predictor of postoperative cardiac morbidity and mortality. The type of morbidity studied by Salis et al. are postoperative blood loss, length of ICU treatment, total length of hospital stays, multiple RBC transfusions, surgery due to bleeding, respiratory, neurological, infection, and kidney complications. ${ }^{14}$

\section{CONCLUSSIONS}

In this study, about one third of patients experienced prolonged ventilation after mitral valve surgery. Factors that influence this event are the duration of ischemic time, aortic clamp time and CPB. Age factors, heart failure, left ventricular dysfunction, and pulmonary hypertension were not significantly associated with ventilator use 24 hours. We suggest to do research with a better design to assess the factors that can influence the incidence of prolonged ventilation after mitral valve surgery in Dr. Sardjito General Hospital. ${ }^{15}$

\section{ACKNOWLEDGEMENT}

Author would like to thank Adika Zhulhi Arjana and Alfin Harjuno Dwiputro for their help in preparing this manuscript.

\section{REFERENCES}

1. Coffey S, Cox B, Williams MJ. Lack of progress in valvular heart disease in the pre-transcatheter aortic valve replacement era: Increasing deaths and minimal change in mortality rate over the past three decades. Am Heart J. 2014; 167(4):562-567.e2. doi: 10.1016/i.ahj.2013.12.030. [PubMed].

2. Ribeiro GS, Tartof SY, Oliveira DWS, Guedes ACS, Reis MG, Riley LW, et al. Surgery for valvular heart disease: a population-based study in a Brazilian urban center. PLoS One. 2012; 7(5):e37855. doi: 10.1371/journal.pone.0037855. [PubMed].

3. Kappetein AP, Head SJ, Genereux P, Piazza N, van Mieghem NM, Blackstone EH, et al. Updated standardized endpoint definitions for transcatheter aortic valve implantation: the Valve Academic Research Consortium-2 consensus document (VARC-2). Eur J Cardiothorac Surg. 2012; 42(5):S4560. doi: $10.1093 /$ ejcts/ezs533. [PubMed]. 
4. Antunes PE, de Oliveira JF, Antunes MJ. Risk-prediction for postoperative major morbidity in coronary surgery. Eur J Cardiothorac Surg. 2009; 35(5):760-6. doi: 10.1016/j.ejcts.2008.10.046. [PubMed].

5. Andrade ING, Moraes Neto FR de, Andrade TG. Use of EuroSCORE as a predictor of morbidity after cardiac surgery. Rev Bras Cir Cardiovasc. 2014; 29(1):9-15. doi: 10.5935/1678-9741.20140005. [PubMed].

6. Priyatno W. Faktor Prognostik Pada Operasi Katup Jantung Di Rsup Dr Sardjito Yogyakarta. [Tesis]. Yogyakarta: Universitas Gajah Mada; 2015.

7. Asmaya AP. Fraksi Ejeksi, Gagal Jantung Kelas Fungsional Nyha Dan Umur Sebagai Faktor Prognostik Pada Operasi Penggantian Katup Mitral Jantung Di Rsup Dr Sardjito. [Tesis]. Yogyakarta: Universitas Gajah Mada; 2017.

8. Yanquez FJ, Clements JM, Grauf D, Merchant AM. Synergistic effect of age and body mass index on mortality and morbidity in general surgery. J Surg Res. 2013; 184(1):89-100. doi: 10.1016/j.jss.2013.05.009. [PubMed].

9. Ruiz-García J, Lerman A, Weisz G, Maehara A, Mintz GS, Fahy M, et al. Age- and gender-related changes in plaque composition in patients with acute coronary syndrome: the PROSPECT study. Eurolntervention. 2012; 8(8):929-38. doi: 10.4244/EIJV8I8A142. [PubMed].

10. Chan KMJ, Punjabi PP, Flather M, Wage R, Symmonds K, Roussin I, et al. Coronary artery bypass surgery with or without mitral valve annuloplasty in moderate functional ischemic mitral regurgitation: final results of the Randomized Ischemic Mitral Evaluation (RIME) trial. Circulation. 2012; 126(21):2502-10. doi: 10.1161/CIRCULATIONAHA.112.143818. [PubMed].

11. Nashef SA, Roques F, Sharples LD, Nilsson J, Smith C, Goldstone AR, et al. EuroSCORE II. 2012; 41(4):734-44. doi: 10.1093/ejcts/ezs043. [PubMed].

12. Azarfarin R, Ashouri N, Totonchi Z, Bakhshandeh H, Yaghoubi A. Factors influencing prolonged icu stay after open heart surgery. Res Cardiovasc Med. 2014; 3(4):e20159. doi: 10.5812/cardiovascmed.20159. [PubMed].

13. Guerrero $M$, Urena $M$, Himbert D, Wang DD, Eleid M, Kodali S, et al. 1-Year Outcomes of Transcatheter Mitral Valve Replacement in Patients With Severe Mitral Annular Calcification. J Am Coll Cardiol. 2018; 71(17):1841-53. doi: 10.1016/i.jacc.2018.02.054. [PubMed].

14. Salis S, Mazzanti V V., Merli G, Salvi L, Tedesco CC, Veglia F, et al. Cardiopulmonary Bypass Duration Is an Independent Predictor of Morbidity and Mortality After Cardiac Surgery. J Cardiothorac Vasc Anesth. 2008; 22(6):814-22. doi: 10.1053/i.jvca.2008.08.004. [PubMed].

15. Al-Githmi I. Does Gender Affect the Outcomes of Multiple Valve Heart Surgery?. Open J Thorac Surg. 2012; 2(1):1-4. doi: 10.4236/ojts.2012.21001. 